\title{
EEG monitoring during anesthesia of a patient under the influence of cocaine
}

\author{
Lopes C.G. ${ }^{1}$, Nunes R.R. ${ }^{2}$, Cavalcante S.L.F. ${ }^{2}$, Fernandes M.B.C. ${ }^{2}$, \\ Nascimento J.C.R. ${ }^{2}$, Ribeiro K.G. ${ }^{2}$ \\ ${ }^{1}$ Hospital Sao Carlos, Dept of Anaesthesiology, Fortaleza, Brazil, \\ ${ }^{2}$ Hospital Geral de Fortaleza, Dept of Anaesthesiology, Fortaleza, Brazil
}

Background: Cocaine is a common recreational drug. Anesthesiologists at times have to manage patients under the influence of cocaine. This drug increases cerebral concentrations of norepinephrine, serotonin and especially dopamine by blocking presynaptic uptake. Complications associated with central vascular changes and direct excitatory effects on the CNS may interfere in anesthetic titration.

Case report: A 27 year-old male with open fracture of the right leg from a motorcycle accident reported using cocaine 3 hours earlier. The patient was submitted to external bone fixation under subarachnoid blockade with isobaric levobupivacaine $(12.5 \mathrm{mg})$. The patient was awake, without agitation, and monitored with NIBP, cardioscopy, SpO2 and bilateral BIS with spectrographic analysis. Midazolam $(10 \mathrm{mg}$ ) was administered, but the effect was short-lived. BIS remained high, with zero burst suppression. The spectrogram revealed power enhancement, especially in the alpha and beta bands (well-defined red patterns) unlike the EEG pattern observed in the wake state without CNS stimulants. The amplitude was momentarily attenuated during the effect of midazolam. No hemodynamic changes occurred and the patient remained cooperative throughout the procedure.

Discussion: EEG monitoring during anesthesia makes it possible to evaluate the depth of anesthesia and detect electrical changes induced by compounds acting on the CNS. Each drug affects the EEG in a specific manner, as observed for cocaine, which enhanced power in all bands.

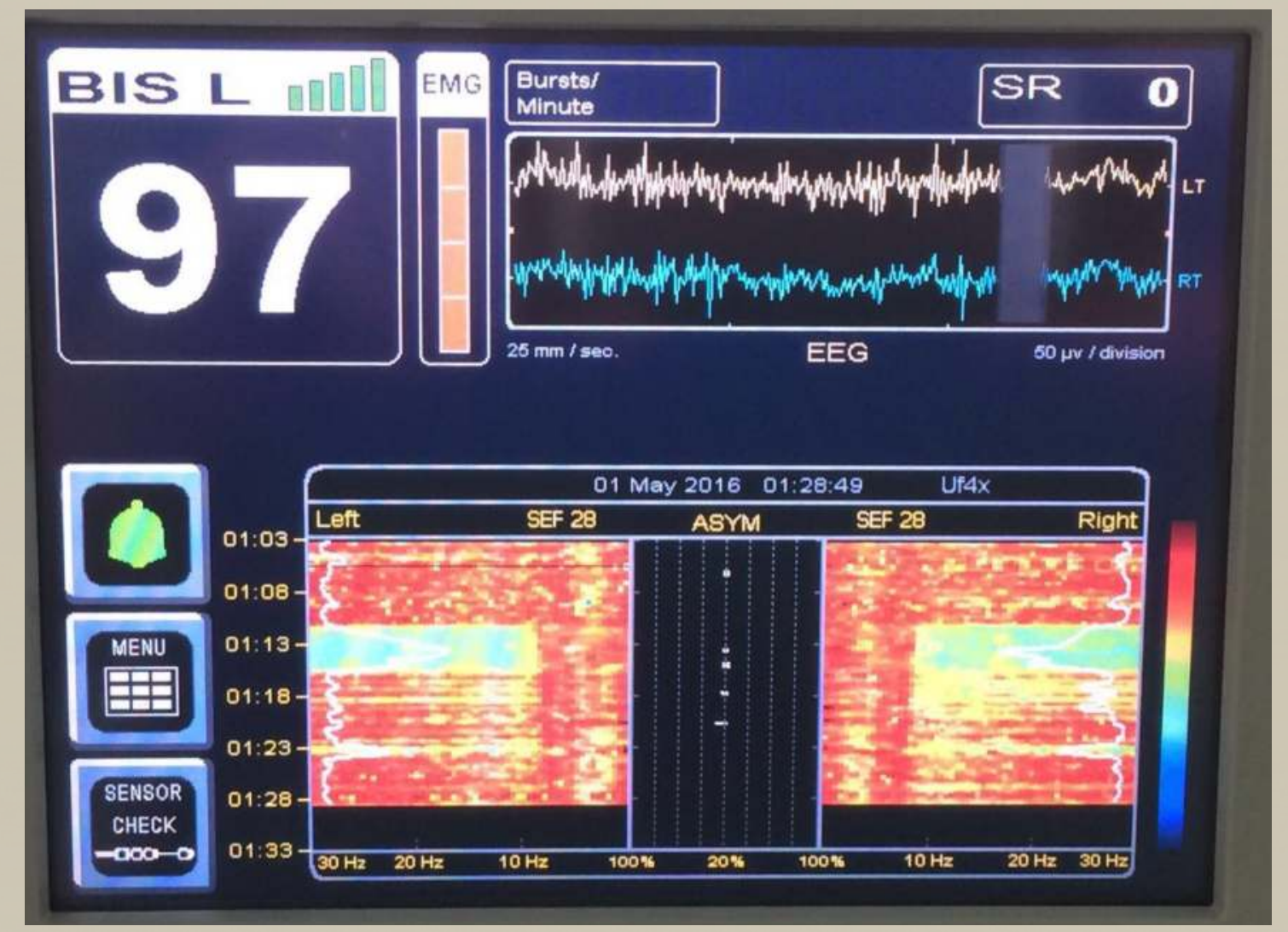

References:

1. Nunes RR, Chaves IMM, Alencar JCG, et al. Bispectral index and other processed parameters of electroencephalogram: an update. Rev Bras Anestesiol 2012; 62: 1: 105-117.

2. Bauer G, Bauer R. EEG, Drug Effects, and Central Nervous System Poisoning. In: Schomer DL, Silva FHL. Niedermeyer's

Electroencephalography: Basic Principles, Clinical Applications, and Related Fields. 6th Ed. Lippincott Williams \& Wilkins. 2011:901-922. 